\title{
DYNAMICS OF A TWO-COUNTRY KALDORIAN MODEL OF BUSINESS CYCLES WITH FIXED EXCHANGE RATES: THE CASE OF SLOVAKIA AND THE CZECH REPUBLIC*
}

ŚLĄSKI

PRZEGLĄD

STATYSTYCZNY

$\mathrm{Nr}$ 18(24)

ISSN 1644-6739

e-ISSN 2449-9765

\section{Petra Cisková, Emília Zimková, Rudolf Zimka}

Matej Bel University in Banská Bystrica, Slovakia

e-mails: petra.ciskova@umb.sk; emilia.zimkova@umb.sk; rudolf.zimka@umb.sk

ORCID: 0000-0002-7226-2160; 0000-0003-1648-8103; 0000-0003-4790-1597

C 2020 Petra Cisková, Emília Zimková, Rudolf Zimka

This work is licensed under the Creative Commons Attribution-ShareAlike 4.0 International License. To view a copy of this license, visit http://creativecommons.org/licenses/by-sa/4.0/

Quote as: Cisková, P., Zimková, E., and Zimka, R. (2020). Dynamics of a two-country Kaldorian model of business cycles with fixed exchange rates: the case of Slovakia and the Czech Republic. Śląki Przegląd Statystyczny, 18(24).

DOI: $10.15611 /$ sps.2020.18.05

\begin{abstract}
In this paper, Asada's five-dimensional nonlinear model describing the dynamic interaction of two regions connected through interregional trade and interregional capital movement with fixed exchange rates is applied to the conditions of Slovakia and the Czech Republic. The functions of consumptions, investments, interest rates, taxes, and net exports involved in the model are constructed based on quarterly data of these two countries from the period 2010-2017. The equilibrium was found and the conditions on the parameters were established, guaranteeing that the Jacobian matrix of the model has a pair of purely imaginary eigenvalues with the remaining three with negative real parts. The bifurcation equation of the model giving the information on the qualitative properties of its solutions around the equilibrium, including the existence of business cycles and their stability/instability, was obtained. Numerical simulations are presented showing that they are fully in compliance with the achieved theoretical results.
\end{abstract}

Keywords: two-country Kaldorian model, fixed exchange rates, equilibrium, stability, business cycles.

* The paper was financially supported by the grant scheme VEGA 1/0785/19 Construction and analysis of dynamic nonlinear models of macroeconomic processes from the Ministry of Education, Science, Research and Sport of the Slovak Republic. The authors would like to thank the anonymous referees for their helpful comments on earlier versions of this paper. 


\section{Introduction}

Nr 18(24)

Asada, Inaba and Misawa (2001) developed and studied a two-regional model of business cycles with fixed exchange rates, which consists of a five-dimensional discrete time system. Asada (2004) introduced and analysed the continuous time version of this model describing the dynamic interaction of two regions which are connected through interregional trade and interregional capital movement. He analysed the question of stability/instability of an equilibrium point of this model and outlined the possibility of the existence of cycles around this equilibrium. The question of the existence of cycles around the equilibrium was rigorously examined by Maličký and Zimka (2010, 2012).

In their paper, the model of Asada (2004) was applied to the conditions of Slovakia and the Czech Republic. The authors studied the dynamic interaction of Slovakia and the Czech Republic in the field of their interregional trade and interregional capital movement. They were interested especially in the existence of equilibrium, its stability/instability and in the existence of business cycles.

It is worth mentioning that the model studied in the paper has two theoretical origins, one of them being the recent development of the dynamic analysis in regional economics and international macroeconomics. Typical examples of such research are by Rosser (1991), Nijkamp and Reggiani (1992), Puu (1997), and Asada, Chiarella, Flaschel and Franke (2003). The second origin is the non-linear business theory originated by Kaldor (1940) and developed by Lorenz (1987, 1993), Gandolfo (2009) and others, called the Kaldorian business cycle theory.

The first studies in the domain of regional economics and international macroeconomics and in the Kaldorian business cycle theory were soon followed by others, e.g. by Asada, Inaba and Misawa (2001). Asada (2004), Asada, Douskos, Kalantonis and Markellos (2010), Asada, Douskos and Markellos (2011), in which the authors studied two-country or two-regional models of Kaldorian business cycles under fixed and flexible exchange rates. In line with this development, open economy extensions of Kaldor's (1940) non-linear business cycle model appeared in the publications by several authors. Asada (1995), Asada, Misawa and Inaba (2000), Asada, Inaba and Misawa (2001), Medved'ová (2011) and Asada, Kalantonis, Markellos and Markellos (2012) extended the Kaldorian business cycle theory to the models of a small open economy under fixed and flexible exchange rates. Further progress in research in particular on questions concerning business cycles was made utilizing new knowledge on limit cycles which can be found, for example in the books by Bibikov (1979), Wiggins (1990), and Kuznetsov (2004). In the domain of regional economics and international macroeconomics one can mention 
Maličký and Zimka (2010, 2012), and in the research on Kaldorian business cycle theory, the studies by Asada, Demetrian and Zimka (2018, 2019).

The paper is arranged as follows. Section 2 introduces Asada's model STATYSTYCZNY (2004). Section 3 is devoted to the application of Asada's model to the case of Slovakia and the Czech Republic. In this section the forms of functions involved in the model were constructed. In Section 4, the estimation of the coefficients of these functions was performed based on data from the period 2010 to 2017 obtained from the database of the National Bank of Slovakia, the Czech Statistical Office and Eurostat. Section 5 is devoted to the analysis of the model. In Section 6, numerical simulations are presented, and Section 7 summarizes the main findings and suggests their other possible generalization.

\section{Presentation of Asada's model}

Asada's model (2004) has the form

$$
\begin{gathered}
\dot{Y}_{i}=\alpha_{i}\left(C_{i}+I_{i}+G_{i}+J_{i}-Y_{i}\right), \alpha_{i}>0, \\
\dot{K}_{i}=I_{i}, \\
\dot{M}_{1}=p_{1} A_{1}, i=1,2,
\end{gathered}
$$

where

$$
\begin{gathered}
C_{i}=c_{i} Y_{i}+C_{i 0}, 0<c_{i}<1, \\
I_{i}=I_{i}\left(Y_{i}, K_{i}, r_{i}\right), \frac{\partial I_{i}}{\partial Y_{i}}>0, \frac{\partial I_{i}}{\partial K_{i}}<0, \frac{\partial I_{i}}{\partial r_{i}}<0, \\
\frac{M_{i}}{p_{i}}=L_{i}\left(Y_{i}, r_{i}\right), \frac{\partial L_{i}}{\partial Y_{i}}>0, \frac{\partial L_{i}}{\partial r_{i}}<0, \\
J_{1}=J_{1}\left(Y_{1}, Y_{2}, E\right), \frac{\partial J_{1}}{\partial Y_{1}}<0, \frac{\partial J_{1}}{\partial Y_{2}}>0, \frac{\partial J_{1}}{\partial E}>0, \\
Q_{1}=\beta\left(\begin{array}{c}
\left.r_{1}-r_{2}-\frac{E^{0}-E}{E}\right), \beta>0, \\
A_{1}=J_{1}+Q_{1}, \\
p_{1} J_{1}+E p_{2} J_{2}=0, \\
p_{1} Q_{1}+E p_{2} Q_{2}=0, \\
\tilde{M}=M_{1}+E M_{2},
\end{array}\right.
\end{gathered}
$$

and the subscript $i, i=1,2$, is the index number of a region. The meanings of the symbols in (1) and (2) are as follows: $Y_{i}$-real regional income, $K_{i}-$ real physical capital stock, $M_{i}$ - nominal money stock, $L_{i}-$ money demand, $C_{i}$ - consumption, $I_{i}$ - net real private investment expenditure on physical 
capital, $G_{i}$ - real government expenditure (fixed), $p_{i}$ - price level, $r_{i}-$ Nr 18(24) nominal rate of interest, $E$ - exchange rate, $E^{0}$ - expected exchange rate, $J_{i}$ - net export in real terms, $Q_{i}$ - net capital flow, $A_{i}$ - total balance of payments in real terms, $\alpha_{i}$-adjustment speed in goods market and $\beta$-degree of capital mobility.

This paper assumed fixed price economy with a fixed exchange rate, therefore we can suppose, normalizing the price levels of two regions, that $p_{1}=p_{2}=1, E=E^{0}$. Further we assumed that nominal interest rates $r_{i}$, $i=1,2$, adjust instantaneously to keep money stock $M_{i}$ and money demand $L_{i}$ in equilibrium. Under these assumptions, taking into account (2) and supposing that $r_{i}$ is implicitly determined by the relations $M_{i}=L_{i}\left(Y_{i}, r_{i}\right), i=1,2$, model (1) takes the form

$$
\begin{gathered}
\dot{Y}_{1}=\alpha_{1}\left(c_{1} Y_{1}+C_{01}+I_{1}\left(Y_{1}, K_{1}, r_{1}\left(Y_{1}, M_{1}\right)\right)+G_{1}+J_{1}\left(Y_{1}, Y_{2}\right)-Y_{1}\right), \\
\dot{K}_{1}=I_{1}\left(Y_{1}, K_{1}, r_{1}\left(Y_{1}, M_{1}\right)\right), \\
\dot{Y}_{2}=\alpha_{2}\left(c_{2} Y_{2}+C_{02}+I_{2}\left(Y_{2}, K_{2}, r_{2}\left(Y_{2}, \tilde{M}-M_{1}\right)\right)+G_{2}-J_{1}\left(Y_{1}, Y_{2}\right)-Y_{2}\right), \\
\dot{K}_{2}=I_{2}\left(Y_{2}, K_{2}, r_{2}\left(Y_{2}, \tilde{M}-M_{1}\right)\right), \\
\dot{M}_{1}=\delta J_{1}\left(Y_{1}, Y_{2}\right)+\beta\left(r_{1}\left(Y_{1}, M_{1}\right)-r_{2}\left(Y_{2}, \tilde{M}-M_{1}\right)\right) .
\end{gathered}
$$

\section{The case of Slovakia and the Czech Republic}

Slovakia and the Czech Republic are small countries with strongly open economies. Although for both of them their largest trade partner is Germany, the authors applied the model to Slovakia and the Czech Republic, taking into account their common history in the context of Czechoslovakia and the very intensive connections after their separation in 1993. Hence, one should look at the developments of incomes, physical capital stocks and money stocks gained by the analysis of the model as only hypothetical. They show how these macroeconomic variables would develop on the assumption that Slovakia and the Czech Republic performed their international trade and international capital movement only between themselves.

In this section we construct the forms of the functions used in the model utilizing quarterly macroeconomic data from the period 2010 to 2017 obtained from the database of the National Bank of Slovakia, the Czech Statistical Office and Eurostat. The authors used these data in the way assuming that they correspond to the situation that Slovakia and the Czech Republic perform their international trade and international capital movement only between themselves.

The function of real income $Y_{i}=Y_{i}\left(C_{i}, I_{i}, G_{i}, J_{i}\right)$ is derived from the expenditure approach for calculating gross domestic product (GDP), that 
combines consumption expenditures $C_{i}$, net real private investment expenditure on physical capital $I_{i}$, government expenditure $G_{i}$ and net export $J_{i}$

Suppose that the consumption $C_{i}$ is a linear function of real income (see e.g. Murakami (2018)). Then $C_{i}$ is given by the formula

$$
C_{i}=c_{i} Y_{i}+C_{0 i}, 0<c_{i}<1,
$$

where $C_{0 i}$ is the autonomous consumption and $c_{i}$ is the marginal propensity to consume.

The net real private investment expenditure on physical capital $I_{i}$ is taken as a non-linear function of real income $Y_{i}$, capital stock $K_{i}$ and interest rate $r_{i}$ which is applied to firms. We consider the investment function $I_{i}$ in the form

$$
I_{i}\left(Y_{i}, K_{i}, r_{i}\right)=\gamma_{i} \sqrt{Y_{i}}-\delta_{i} \sqrt{K_{i}}-\varepsilon_{i} r_{i}-i_{0 i},
$$

where $\gamma_{i}, \delta_{i}, \varepsilon_{i}, i_{0 i}$ are constant parameters, and assume that the money market is in equilibrium, e. g. $L_{i}=M_{i}$, and that interest rate $r_{i}$ is implicitly determined by this relation. It is taken in the form

$$
r_{i}=\mu_{i} \sqrt{Y_{i}}-v_{i} M_{i}-r_{0 i}
$$

where $\mu_{i}, v_{i}, r_{0 i}$ are constant parameters.

Government expenditures $G_{i}$, which ensure the basic functions of the government, are assumed to be fixed.

The function of net export $J_{1}$ depends on the national incomes of both analyzed regions $Y_{1}, Y_{2}$ and on the exchange rate $E$. The authors worked with the data of the Czech Republic expressed in respect to the euro, hence exchange rate $E$ in model (1) is $E=1$. The function of net export takes the form

$$
J_{1}=-\varphi Y_{1}+\psi Y_{2}+j_{0},
$$

where $\varphi, \psi, j_{0}$ are constant parameters.

The total balance of payments $A_{1}$ is given by the relation $A_{1}=J_{1}+Q_{1}$. The capital account $Q_{1}$ has the form

$$
Q_{1}=\beta\left(r_{1}-r_{2}\right), \beta>0,
$$

where $\beta$ is the degree of capital mobility.

As $\tilde{M}=M_{1}+M_{2}$, it is sufficient to have in the model only the equation for the development of $M_{1}$, because $M_{2}=\tilde{M}-M_{1}$.

Putting the functions (4) to (8) into the model (3), we obtain the model 


$$
\begin{gathered}
\dot{Y}_{1}=\alpha_{1}\left(c_{1} Y_{1}+C_{01}+\gamma_{1} \sqrt{Y_{1}}-\delta_{1} \sqrt{K_{1}}-\varepsilon_{1}\left(\mu_{1} \sqrt{Y_{1}}-v_{1} M_{1}-r_{01}\right)-\right. \\
\left.i_{01}+G_{1}-\varphi Y_{1}+\psi Y_{2}+j_{0}-Y_{1}\right), \\
\dot{K}_{1}=\gamma_{1} \sqrt{Y_{1}}-\delta_{1} \sqrt{K_{1}}-\varepsilon_{1}\left(\mu_{1} \sqrt{Y_{1}}-v_{1} M_{1}-r_{01}\right)-i_{01}, \\
\dot{Y}_{2}=\alpha_{2}\left(c_{2} Y_{2}+C_{02}+\gamma_{2} \sqrt{Y_{2}}-\delta_{2} \sqrt{K_{2}}-\varepsilon_{2}\left(\mu_{2} \sqrt{Y_{2}}-v_{2}\left(\tilde{M}-M_{1}\right)-r_{02}\right)-\right. \\
\left.i_{02}+G_{2}+\varphi Y_{1}-\psi Y_{2}-j_{0}-Y_{2}\right), \\
\dot{K}_{2}=\gamma_{2} \sqrt{Y_{2}}-\delta_{2} \sqrt{K_{2}}-\varepsilon_{2}\left(\mu_{2} \sqrt{Y_{2}}-v_{2}\left(\tilde{M}-M_{1}\right)-r_{02}\right)-i_{02}, \\
\dot{M}_{1}=\delta\left(-\varphi Y_{1}+\psi Y_{2}+j_{0}\right)+ \\
\beta\left(\mu_{1} \sqrt{Y_{1}}-v_{1} M_{1}-r_{01}-\mu_{2} \sqrt{Y_{2}}+v_{2}\left(\tilde{M}-M_{1}\right)+r_{02}\right) .
\end{gathered}
$$

Later in the paper model (9) is simply called the model.

\section{Estimation of the coefficients in the model}

The model describes the development of real income, investments and the nominal money stocks of Slovakia and the Czech Republic. The functions of the model were constructed based on the macroeconomic uniqueness of both countries. The period 2010-2017, from which the time series data were taken, is characterized as a the post-crisis period of the financial crisis in 2008. This financial crisis influenced economies of the whole world, including those of Slovakia and the Czech Republic. Fiscal and monetary policy makers in Slovakia and the Czech Republic, and also those in the European Union sought ways to mitigate the effects of the crisis through a number of support mechanisms and interventions. The aim was to stabilize price levels, promote economic growth and reduce unemployment, for instance the European Central Bank and the Czech National Bank used quantitative easing to increase money supply and reduce interest rates in economies to support in particular the investments of companies. Investment in Slovakia and the Czech Republic was also positively influenced by the European Structural Funds.

Figure 1 shows the cyclical component of the investments and real incomes in the Czech Republic and Slovakia in 2010-2017. One can see that the volatilities in investments in both countries were more intensive when compared with their real incomes. The cyclical components were obtained using the Hodrick-Prescott filter with the smoothing parameter 
1600 for quarterly data ${ }^{1}$. The investment fluctuations of both countries strongly influenced their economic developments.
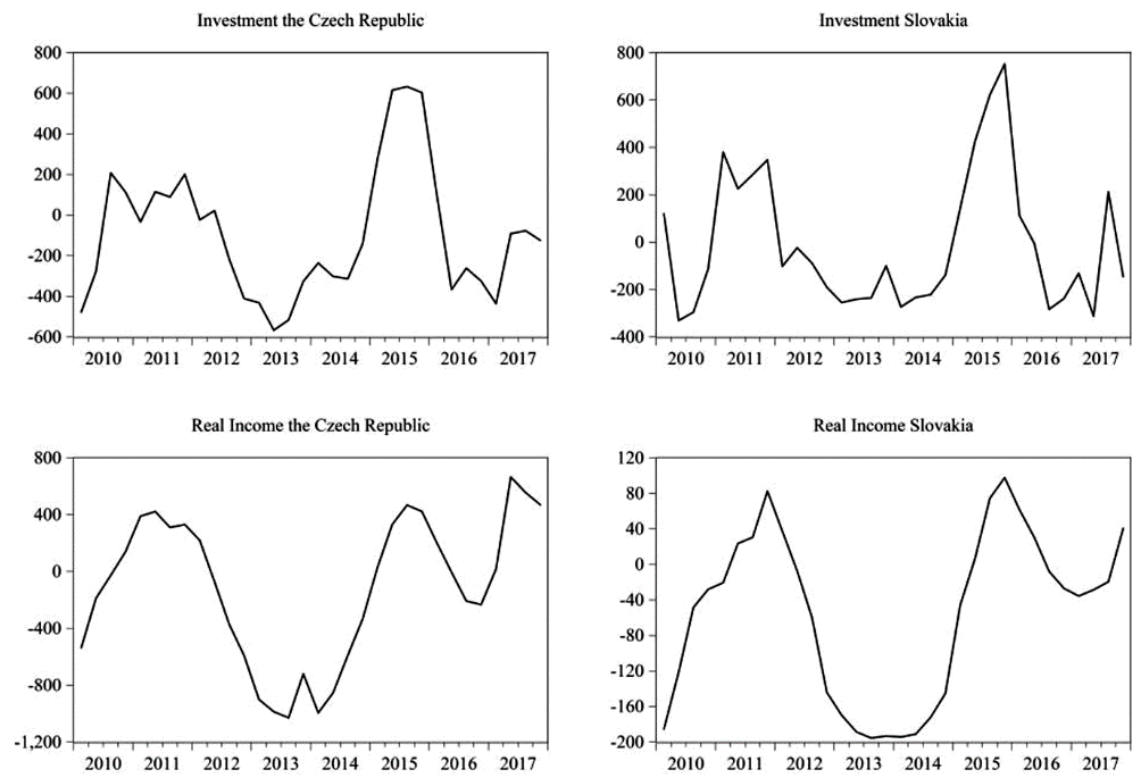

Fig. 1. Cyclical components of real incomes and investments

Source: own elaboration.

As already mentioned in Section 3, this analysis assumed that Slovakia and the Czech Republic conduct their international trade and international capital movement only between themselves. The development of money stocks $M_{i}$ depends on total balance of payments $A_{i}$, respectively on net export $J_{i}$ and capital flows $Q_{i}$, between both countries, $i=1,2$, where in the rest of this paper index 1 marks Slovakia and index 2 the Czech Republic. Due to the large scale of the quantitative easing program of the European Central Bank and the Czech National Bank, it was necessary to adjust the money stocks of both countries. The authors found the common nominal money stock $\tilde{M}$ by an expert estimation.

The functions in the model are non-linear only in the variables $Y_{i}, K_{i}$. The estimations of the functions' coefficients used in the model were gained by regression analysis. The authors suppose assumed that the government expenditures in both countries were at a constant level, setting them up as their average values during the years 2010-2017. The authors obtained

\footnotetext{
${ }^{1}$ The authors used software support such as EViews and Wolfram Mathematica.
} 
$G_{1}=3428.8$ and $G_{2}=8054.6$, where the unit of financial value is taken as

1 million euros.

Monetary and fiscal policy makers can appropriately use the coefficients $\delta$ and $\beta$ to manage international trade and international capital movement. In this case, the authors set them at $\delta=1$ and $\beta=4000$.

Table 1 summarizes the achieved results for Slovakia and the Czech Republic.

Table 1. Estimation of the coefficients

\begin{tabular}{|c|c|c|c|}
\hline \multicolumn{2}{|c|}{ Slovakia } & \multicolumn{2}{|c|}{ The Czech Republic } \\
\hline \multicolumn{4}{|c|}{ Consumption Function } \\
\hline$c_{1}$ & $\begin{array}{l}0.305 * * * \\
(0.0173)\end{array}$ & $c_{2}$ & $\begin{array}{c}0.4228 * * * \\
(0.0128)\end{array}$ \\
\hline$C_{01}$ & $\begin{array}{c}4314.498 * * * \\
(301.575)\end{array}$ & $\mathrm{C}_{02}$ & $\begin{array}{c}2380.622 * * * \\
(523.855)\end{array}$ \\
\hline Adjusted $R^{2}$ & 0.8584 & Adjusted $R^{2}$ & 0.973 \\
\hline \multicolumn{4}{|c|}{ Investment Function } \\
\hline$\gamma_{1}$ & $\begin{array}{c}339.714 * * * \\
(47.021)\end{array}$ & $\gamma_{1}$ & $\begin{array}{c}241.638 * * * \\
(12.263)\end{array}$ \\
\hline$\delta_{1}$ & $\begin{array}{c}-53.414 * * * \\
(9.1661)\end{array}$ & $\delta_{2}$ & $\begin{array}{c}-14.97 * * * \\
(1.705)\end{array}$ \\
\hline$\varepsilon_{1}$ & $\begin{array}{c}-63899.49 * * * \\
(14118.89)\end{array}$ & $\varepsilon_{2}$ & $\begin{array}{c}-37465.04 * * * \\
(12160.54)\end{array}$ \\
\hline$i_{01}$ & $\begin{array}{c}-4918.939 * * * \\
(447.909)\end{array}$ & $i_{02}$ & $\begin{array}{c}-20264.10 * * * \\
(1608.59)\end{array}$ \\
\hline Adjusted $R^{2}$ & 0.972 & Adjusted $R^{2}$ & 0.958 \\
\hline \multicolumn{4}{|c|}{ Function of Nominal Rate of Interest } \\
\hline$\mu_{1}$ & $\begin{array}{c}0.001084 * * * \\
(0.000256)\end{array}$ & $\mu_{2}$ & $\begin{array}{c}0.001089 * * * \\
(0.000234)\end{array}$ \\
\hline$\nu_{1}$ & $\begin{array}{c}-0.00000196 * * * \\
(0.000000245)\end{array}$ & $v_{2}$ & $\begin{array}{c}-0.000000585 * * * \\
(0.00000007)\end{array}$ \\
\hline$r_{01}$ & $\begin{array}{l}-0.052 * \\
(0.0265)\end{array}$ & $r_{02}$ & $\begin{array}{c}-0.1145 * * * \\
(0.039)\end{array}$ \\
\hline Adjusted $R^{2}$ & 0.8557 & Adjusted $R^{2}$ & 0.8939 \\
\hline \multicolumn{4}{|c|}{ Function of Net Export } \\
\hline & $\varphi$ & $\begin{array}{c}-0.4025 * * * \\
(0.0734)\end{array}$ & \\
\hline & $\psi$ & $\begin{array}{c}0.1168 * * * \\
(0.032)\end{array}$ & \\
\hline & $j_{0}$ & $\begin{array}{c}3162.951 * * * \\
(222.987)\end{array}$ & \\
\hline & Adjusted $R^{2}$ & 0.8802 & \\
\hline
\end{tabular}

Notes: standard errors are in parentheses. Symbols *, **, *** denote significance at the 10,5 or 1 percent levels.

Source: authors own elaboration. 
Based on the obtained results the functions in the model are

$$
\begin{gathered}
C_{1}=0.305 Y_{1}+4314.498, \\
I_{1}\left(Y_{1}, K_{1}, r_{1}\right)=339.714 \sqrt{Y_{1}}-53.414 \sqrt{K_{1}}-63899.49 r_{1}-4918.939, \\
r_{1}=1.084 \times 10^{-3} \sqrt{Y_{1}}-0.196 \times 10^{-5} M_{1}-0.052, \\
J_{1}\left(Y_{1}, Y_{2}\right)=-0.4025 Y_{1}+0.1168 Y_{2}+3162.951, \\
C_{2}=0.4228 Y_{2}+2380.622, \\
I_{2}\left(Y_{2}, K_{2}, r_{2}\right)=241.638 \sqrt{Y_{2}}-14.97 \sqrt{K_{2}}-37465.04 r_{2}-20264.10, \\
r_{2}=0.001089 \sqrt{Y_{2}}-0.585 \times 10^{-6} M_{2}-0.1145, \\
J_{2}\left(Y_{1}, Y_{2}\right)=0.4025 Y_{1}-0.1168 Y_{2}-3162.951 .
\end{gathered}
$$

\section{Analysis of the model}

Equilibrium values $\Gamma^{*}=\left(Y_{1}^{*}, K_{1}^{*}, Y_{2}^{*}, K_{2}^{*}, M_{1}^{*}\right)$ of the model are determined by the system of equations

$$
\begin{gathered}
C_{1}+G_{1}+J_{1}\left(Y_{1}, Y_{2}\right)-Y_{1}=0, \\
I_{1}\left(Y_{1}, K_{1}, r_{1}\left(Y_{1}, M_{1}\right)\right)=0, \\
C_{2}+G_{2}-J_{1}\left(Y_{1}, Y_{2}\right)-Y_{2}=0, \\
I_{2}\left(Y_{2}, K_{2}, r_{2}\left(Y_{2}, M_{2}\right)\right)=0, \\
J_{1}\left(Y_{1}, Y_{2}\right)+\beta\left[r_{1}\left(Y_{1}, M_{1}\right)-r_{2}\left(Y_{2}, M_{2}\right)\right]=0,
\end{gathered}
$$

where the functions in these equations are given in (10). By solving equations (11), we obtained for the equilibrium $\Gamma^{*}$ the values

$$
\begin{gathered}
\Gamma^{*}=\left(Y_{1}^{*}=11775.851, K_{1}^{*}=583375.844, Y_{2}^{*}=17309.478,\right. \\
\left.K_{2} *=702767.033, M_{1}^{*}=104159.808\right) .
\end{gathered}
$$

As the majority of coefficients in the specified functions and the numbers in other gained expressions have a lot of digits after their decimal point, it was necessary to round them in the paper. Exact values can be provided on request by the corresponding author.

Relevant information on the stability/instability of equilibrium $\Gamma^{*}$ and the existence of limit cycles around equilibrium $\Gamma^{*}$ can be obtained in particular from the bifurcation equation of the model. To obtain this equation, one should perform the standard procedure (see e.g. Kuznetsov (2004), Asada et al. $(2018 ; 2019))$ which consists of the following steps: 
- $\quad$ set up the Jacobian matrix of the model at equilibrium $\Gamma^{*}$, determine a bifurcation value, and calculate the corresponding eigenvalues,

- translate the equilibrium $\Gamma^{*}=\left(Y_{1}^{*}, K_{1}^{*}, Y_{2}^{*}, K_{2}^{*}, M_{1}^{*}\right)$ into the origin $\Gamma_{0}^{*}=(0,0,0,0,0)$ and the bifurcation value into zero,

- transform the model to the form with the Jordan linear approximation matrix,

- transform the obtained model to its partial normal form on the invariant surface,

- construct the bifurcation equation.

\section{The Jacobian matrix of the model}

The Jacobian matrix has the form

$$
J\left(\Gamma^{*}, \alpha_{1}, \alpha_{2}\right)=\left(\begin{array}{ccccc}
\alpha_{1} a_{11} & \alpha_{1} a_{12} & \alpha_{1} a_{13} & \alpha_{1} a_{14} & \alpha_{1} a_{15} \\
a_{21} & a_{22} & a_{23} & a_{24} & a_{25} \\
\alpha_{2} a_{31} & \alpha_{2} a_{32} & \alpha_{2} a_{33} & \alpha_{2} a_{34} & \alpha_{2} a_{35} \\
a_{41} & a_{42} & a_{43} & a_{44} & a_{45} \\
a_{51} & a_{52} & a_{53} & a_{54} & a_{55}
\end{array}\right),
$$

where

$$
\begin{aligned}
& a_{11}=0.149, a_{12}=-0.350, a_{13}=0.117, a_{14}=0, a_{15}=0.125, a_{21}=1.246, \\
& a_{22}=-0.035, a_{23}=0, a_{24}=0, a_{25}=0.125, a_{31}=0.403 \alpha_{2}, a_{32}=0, a_{33}=0.069 \alpha_{2,}, \\
& a_{34}=-0.009 \alpha_{2,}, a_{35}=-0.022 \alpha_{2}, a_{41}=0, a_{42}=0, a_{43}=0.763, a_{44}=-0.009, \\
& a_{45}=-0.022, a_{51}=-0.383, a_{52}=0, a_{53}=0.100, a_{54}=0, a_{55}=-0.010 .
\end{aligned}
$$

So far, the parameters $\alpha_{1}, \alpha_{2}$ are free. It was found that the values of parameters $\alpha_{1}, \alpha_{2}$ which guarantee that the Jacobian matrix has a pair of purely imaginary eigenvalues with the remaining four with negative real parts are $\alpha_{1}=0.034056, \alpha_{2}=0.062706$. We will call these values the critical values of parameters $\alpha_{1}, \alpha_{2}$. The eigenvalues corresponding to these critical values are

$$
\begin{gathered}
\lambda_{1}=0.018957 i, \lambda_{2}=-0.018957 i, \lambda_{3}=-0.004055 \\
\lambda_{4}=-0.020307-0.05400 i, \lambda_{5}=-0.020307+0.05400 i, i=\sqrt{-1} .
\end{gathered}
$$

We take parameter $\alpha_{2}$ as the bifurcation parameter with its bifurcation value $\alpha_{2}{ }^{*}=\alpha_{2}=0.062706$. This means that in a further procedure was 
studied of the behaviour of solutions around the equilibrium in a small neighborhood of $\alpha_{2}{ }^{*}=0.062706$ at fixed $\tilde{\alpha}_{1}=\alpha_{1}=0.034056$.

The form of the model after the translation of the equilibrium $\Gamma^{*}$ into the origin and the bifurcation parameter $\alpha_{2}{ }^{*}$ into zero.

Having performed the translation of the equilibrium $\Gamma^{*}=\left(Y_{1}^{*}, K_{1}^{*}, Y_{2}^{*}, K_{2}^{*}, M_{1}^{*}\right)$ into the origin $\Gamma_{0}^{*}=(0,0,0,0,0)$ by relations $x_{1}=Y_{1}-Y_{1}^{*}, x_{2}=K_{1}-K_{1}^{*}, x_{3}=Y_{2}-Y_{2}^{*}, x_{4}=K_{2}-K_{2}^{*}, x_{5}=M_{1}-M_{1}^{*}$, the translation of the bifurcation parameter $\alpha_{2}{ }^{*}$ into zero by the relation $\tau=\alpha_{2}-\alpha_{2}{ }^{*}$, and the Taylor expansion of the obtained model at $x=0, x=\left(x_{1}, x_{2}, x_{3}, x_{4}, x_{5}\right)$, after a slight adjustment the model is

$$
\dot{x}=\tilde{J}\left(\Gamma^{*}, \tilde{\alpha}_{1}, \alpha_{2}^{*}\right) x+X(x, \tau),
$$

where the matrix $\tilde{J}\left(\Gamma^{*}, \tilde{\alpha}_{1}, \alpha_{2}^{*}\right)$ is obtained from the Jacobian matrix (12) substituting the parameters $\alpha_{1}, \alpha_{2}$ by the values $\alpha_{1}=0.034056$, $\alpha_{2}^{*}=0.062706$, respectively.

\section{Transformation of model (13) to the form with the Jordan linear approximation matrix}

Performing in model (13) the transformation

$$
x=M z, z=\left(z_{1}, z_{2}, z_{3}, z_{4}, z_{5}\right),
$$

where matrix $M$ consists of the eigenvectors of matrix $\tilde{J}\left(\Gamma^{*}, \tilde{\alpha}_{1}, \alpha_{2}{ }^{*}\right)$, we obtain the model

$$
\begin{aligned}
& \dot{z}_{1}=\lambda_{1} z_{1}+Z_{1}\left(z_{1}, z_{2}, z_{3}, z_{4}, z_{5}, \tau\right), \\
& \dot{z}_{2}=\lambda_{2} z_{2}+Z_{2}\left(z_{1}, z_{2}, z_{3}, z_{4}, z_{5}, \tau\right), \\
& \dot{z}_{3}=\lambda_{3} z_{3}+Z_{3}\left(z_{1}, z_{2}, z_{3}, z_{4}, z_{5}, \tau\right), \\
& \dot{z}_{4}=\lambda_{4} z_{4}+Z_{4}\left(z_{1}, z_{2}, z_{3}, z_{4}, z_{5}, \tau\right), \\
& \dot{z}_{5}=\lambda_{5} z_{5}+Z_{5}\left(z_{1}, z_{2}, z_{3}, z_{4}, z_{5}, \tau\right),
\end{aligned}
$$

$\lambda_{2}=\bar{\lambda}_{1}, z_{2}=\bar{z}_{1}, Z_{2}=\bar{Z}_{1}$, where the bar means complex conjugate expression.

Transformation of model (14) to its partial normal form on the invariant surface 
Polynomial transformation

$$
z=u+h\left(u_{1}, u_{2}, \tau\right), u=\left(u_{1}, u_{2}, u_{3}, u_{4}, u_{5}\right), h=\left(h_{1}, h_{2}, h_{3}, h_{4}, h_{5}\right),
$$

where

$$
h_{j}\left(u_{1}, u_{2}, \tau\right)=\sum_{m_{1}+m_{2}+m \geq 2, m \in\{0,1\}}^{4-2 m} h_{j}^{\left(m_{1}, m_{2}, m\right)} u_{1}^{m_{1}} u_{2}^{m_{2}} \tau^{m}, j=1,2,3,4,5,
$$

transforms model (14) into its partial normal form on the invariant surface (see e.g. Bibikov (1979), Maličký and Zimka (2010))

$$
\begin{gathered}
\dot{u}_{1}=\lambda_{1} u_{1}+\sigma_{1} u_{1} \tau+\sigma_{2}\left(u_{1}\right)^{2} u_{2}+U^{0}(u, \tau)+U^{*}(u, \tau), \\
\dot{u}_{2}=\lambda_{2} u_{2}+\bar{\sigma}_{1} u_{2} \varepsilon+\bar{\sigma}_{2} u_{1}\left(u_{2}\right)^{2}+\bar{U}^{0}(u, \tau)+\bar{U}^{*}(u, \tau), \\
\dot{u}_{3}=\lambda_{3} u_{3}+H_{3}^{0}(u, \tau)+H_{3}^{*}(u, \tau), \\
\dot{u}_{4}=\lambda_{4} u_{4}+H_{4}^{0}(u, \tau)+H_{4}^{*}(u, \tau), \\
\dot{u}_{5}=\lambda_{5} u_{5}+H_{5}^{0}(u, \tau)+H_{5}^{*}(u, \tau),
\end{gathered}
$$

where

$$
\begin{gathered}
(\otimes)^{0}\left(u_{1}, u_{2}, 0,0,0, \tau\right)=0 \\
(\otimes)^{*}\left(\sqrt{|\tau|} u_{1}, \sqrt{|\tau|} u_{2}, \sqrt{|\tau|} u_{3}, \sqrt{|\tau|} u_{4}, \sqrt{|\tau|} u_{5}\right)=O\left((\sqrt{|\tau|})^{5}\right) .
\end{gathered}
$$

The resonant terms $\sigma_{1}$ and $\sigma_{2}$ in (15), determined by the formulae

$$
\begin{gathered}
\sigma_{1}=\frac{\partial^{2} Z_{1}}{\partial z_{1} \partial \tau} \\
\sigma_{2}=\frac{1}{2 \lambda_{2}} \frac{\partial^{2} Z_{1}}{\partial z_{1}^{2}} \frac{\partial^{2} Z_{1}}{\partial z_{1} \partial z_{2}}+\frac{1}{6 \lambda_{1}} \frac{\partial^{2} Z_{1}}{\partial z_{2}^{2}} \frac{\partial^{2} Z_{2}}{\partial z_{1}^{2}}+\frac{1}{\lambda_{1}} \frac{\partial^{2} Z_{1}}{\partial z_{1} \partial z_{2}} \frac{\partial^{2} Z_{2}}{\partial z_{1} \partial z_{2}}- \\
\frac{1}{\lambda_{3}} \frac{\partial^{2} Z_{1}}{\partial z_{1} \partial z_{3}} \frac{\partial^{2} Z_{3}}{\partial z_{1} \partial z_{2}}-\frac{1}{\lambda_{4}} \frac{\partial^{2} Z_{1}}{\partial z_{1} \partial z_{4}} \frac{\partial^{2} Z_{4}}{\partial z_{1} \partial z_{2}}-\frac{1}{\lambda_{5}} \frac{\partial^{2} Z_{1}}{\partial z_{1} \partial z_{5}} \frac{\partial^{2} Z_{5}}{\partial z_{1} \partial z_{2}}+ \\
\frac{1}{2\left(2 \lambda_{1}-\lambda_{3}\right)} \frac{\partial^{2} Z_{1}}{\partial z_{2} \partial z_{3}} \frac{\partial^{2} Z_{3}}{\partial z_{1}^{2}}+\frac{1}{2\left(2 \lambda_{1}-\lambda_{4}\right)} \frac{\partial^{2} Z_{1}}{\partial z_{2} \partial z_{4}} \frac{\partial^{2} Z_{4}}{\partial z_{1}^{2}}+ \\
\frac{1}{2\left(2 \lambda_{1}-\lambda_{5}\right)} \frac{\partial^{2} Z_{1}}{\partial z_{2} \partial z_{5}} \frac{\partial^{2} Z_{5}}{\partial z_{1}^{2}}+\frac{1}{2} \frac{\partial^{3} Z_{1}}{\partial z_{1}^{2} \partial z_{2}},
\end{gathered}
$$

while all derivatives are calculated at $z_{i}=0, i=1,2,3,4,5$, and $\tau=0$, are 


$$
\begin{gathered}
\sigma_{1}=0.029926566+0.0293471 i, \\
\sigma_{2}=2.45953893 \times 10^{-11}+4.51584999 \times 10^{-12} i .
\end{gathered}
$$

In polar coordinates $u_{1}=r e^{i \phi}, u_{2}=r e^{-i \phi}, u_{j}=v_{j}, j=3,4,5$, model (15) has the form

$$
\begin{gathered}
\dot{r}=r\left(\zeta r^{2}+\vartheta \tau\right)+R^{0}(r, \phi, v, \tau)+R^{*}(r, \phi, v, \tau), \\
\varphi=\omega_{0}+\kappa \tau+\rho r^{2}+\frac{1}{r}\left(\Phi^{0}(r, \phi, v, \tau)+\Phi^{*}(r, \phi, v, \tau)\right), \\
\dot{v}_{3}=\lambda_{3} v_{3}+V_{3}^{0}(r, \phi, v, \tau)+V_{3}^{*}(r, \phi, v, \tau), \\
\dot{v}_{4}=\lambda_{4} v_{4}+V_{4}^{0}(r, \phi, v, \tau)+V_{4}^{*}(r, \phi, v, \tau), \\
\dot{v}_{5}=\lambda_{5} v_{5}+V_{5}^{0}(r, \phi, v, \tau)+V_{5}^{*}(r, \phi, v, \tau),
\end{gathered}
$$

where $\zeta=\operatorname{Re} \sigma_{2}, \vartheta=\operatorname{Re} \sigma_{1}, \kappa=\operatorname{Im} \sigma_{1}, \rho=\operatorname{Im} \sigma_{2}, \nu=\left(v_{3}, v_{4}, v_{5}\right)$, and the symbols $(\otimes)^{0},(\otimes)^{*}$ have the same meaning as in model (15).

The equation

$$
\zeta r^{2}+\vartheta \tau=0
$$

from (17) is the bifurcation equation of model (13) in which the coefficients of the functions are substituted by their specified values given in (10).

Using the results from the bifurcation theory (see e. g. Wiggins (1990), Kuznetsov (2004)), the following theorem can be proposed.

Theorem. Let $\zeta$ and $\vartheta$ be the coefficients in bifurcation equation (17). Then it holds:

i) If $\zeta<0$, then there exists in model (13) a stable limit cycle for every small enough $\tau>0$ if $\vartheta$ is positive, and for every small enough $\tau<0$ if $\vartheta$ is negative.

ii) If $\zeta>0$, then there exists in model (13) an unstable limit cycle for every small enough $\tau<0$ if $\vartheta$ is positive, and for every small enough $\tau>0$ if $\vartheta$ is negative.

Substituting $\zeta$ and $\vartheta$ in (18) by their corresponding values from (16), we obtain the bifurcation equation

$$
2.45953893 \times 10^{-11} r^{2}+2.9926566 \times 10^{-2} \tau=0 .
$$


As both values of $\zeta$ and $\vartheta$ are positive, we find according to the Nr 18(24) theorem that in model (13) exists an unstable (subcritical) limit cycle for every small enough $\tau<0$. This means, coming back from parameter $\tau$ to parameter $\alpha_{2}$, that the unstable limit cycle arises for every $\alpha_{2}<\alpha_{2}{ }^{*}$ which is rather close to $\alpha_{2}{ }^{*}$.

\section{Numerical simulations}

Figure 2 shows, on the basis of the obtained theoretical results, an outline of the behaviour of the solutions in model (9) in in a small neighbourhood of the equilibrium $\Gamma^{*}$ with respect to the values of $\alpha_{2}$ from a small vicinity of the bifurcation value $\alpha_{2}{ }^{*}$ (see e.g. Wiggins (1990)).

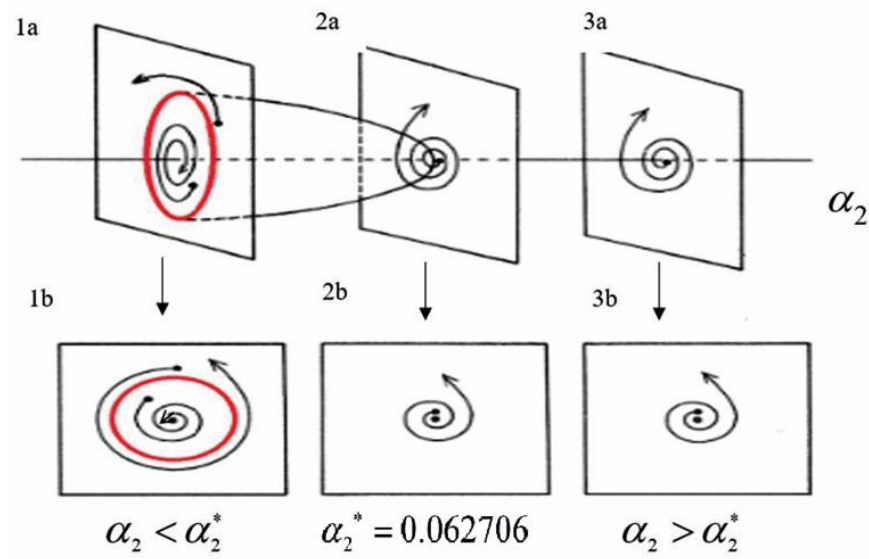

Fig. 2. An outline of the Hopf bifurcation in a small neighbourhood of the bifurcation value $\alpha_{2}{ }^{*}$

Source: own elaboration.

The parts $1 \mathrm{a}$ and $1 \mathrm{~b}$ show that the limit cycle is unstable (subcritical) and equilibrium $\Gamma^{*}$ is stable at the values $\alpha_{2}<\alpha_{2}{ }^{*}$ for $\alpha_{2}$ sufficiently close to the bifurcation value $\alpha_{2}{ }^{*}$. According to the theory of bifurcation, equilibrium $\Gamma^{*}$ is unstable for the values $\alpha_{2} \geq \alpha_{2}{ }^{*}$. This means that at the value of parameter $\alpha_{2}{ }^{*}=0.062706$, the qualitative behaviour of the solutions of the model around its equilibrium changes abruptly.

Figures 3 to 6 show that the behaviour of the solutions of the model in a small neighbourhood of the equilibrium $\Gamma^{*}$ with respect to changes in 
the values of parameter $\alpha_{2}$ in a small vicinity of $\alpha_{2}{ }^{*}$ are fully in compliance with the obtained theoretical results.

Note. These findings also include some results obtained by Asada in (2004). Specifically, the authors found conditions with respect to the bifurcation parameter $\alpha_{2}$, under which equilibrium $\Gamma^{*}$ is stable in the long run (in Asada's Proposition 1, situation (i)), and under which equilibrium $\Gamma^{*}$ is unstable (the situation (ii)). These situations are shown in Figure 2.
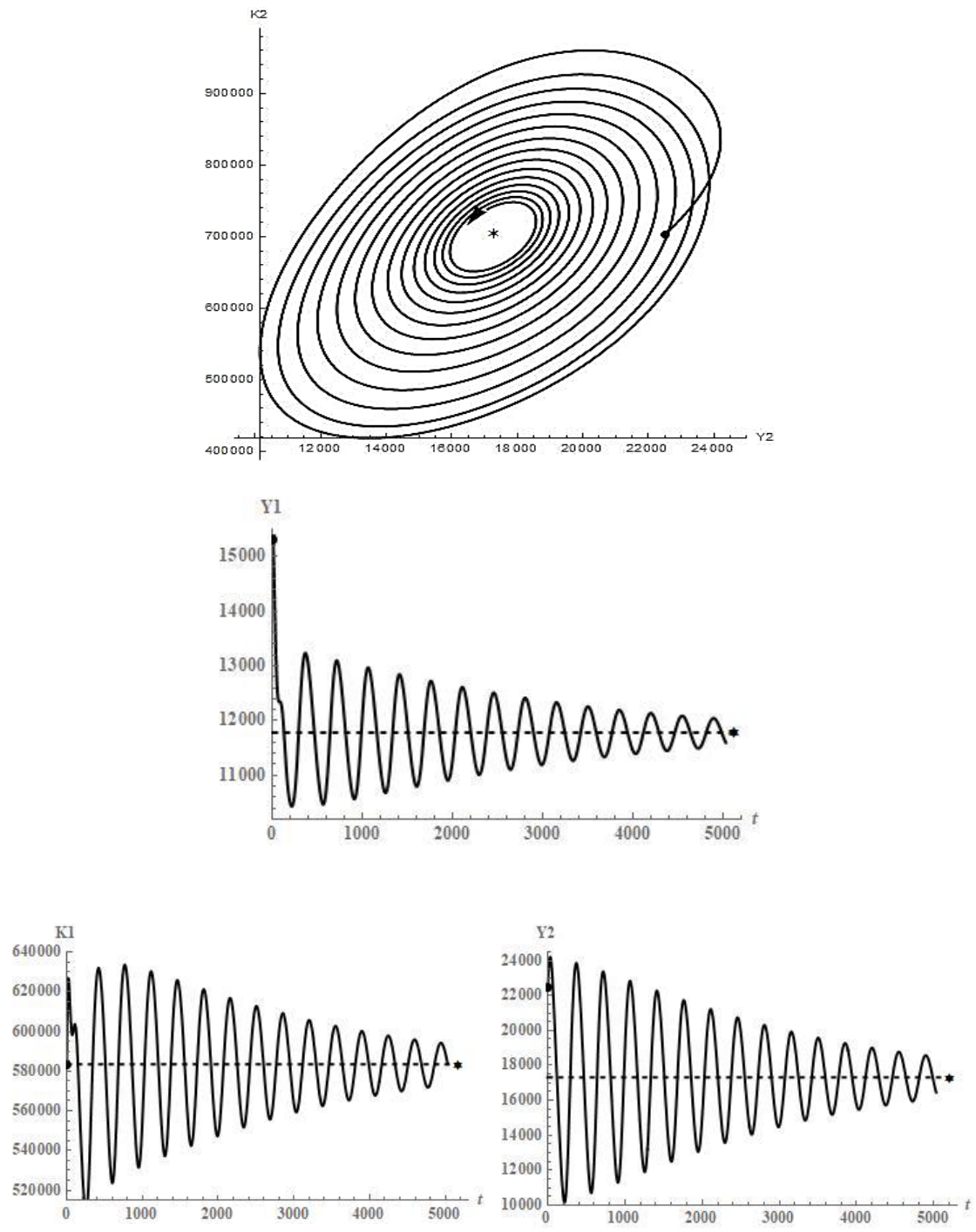
PRZEGLAD STATYSTYCZNY

Nr 18(24)
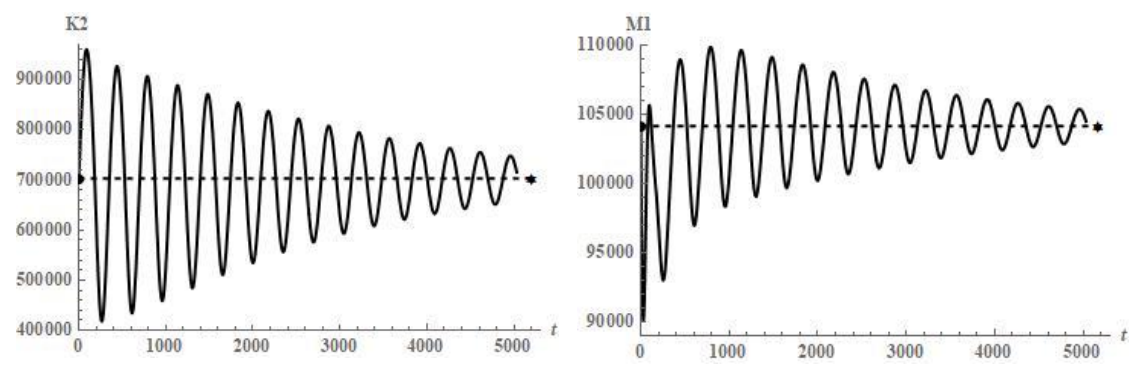

Fig. 3. The projection of the solution into the plane $O_{Y_{2}, K_{2}}$ and the courses of its individual variables at $\alpha_{2}=0.9 \alpha_{2}^{*}$ with the initial values $Y_{10}=1.3 Y_{1}^{*}, K_{10}=K_{1}^{*}$, $Y_{20}=1.3 Y_{2}^{*}, K_{20}=K_{2}^{*}, M_{10}=M_{1}^{*}$

Source: own elaboration.

Figure 3 shows the solution which starts in the domain of the equilibrium's attraction (in the inner part of the unstable limit cycle's repelling domain). One can see that the solution goes to equilibrium $\Gamma^{*}$.

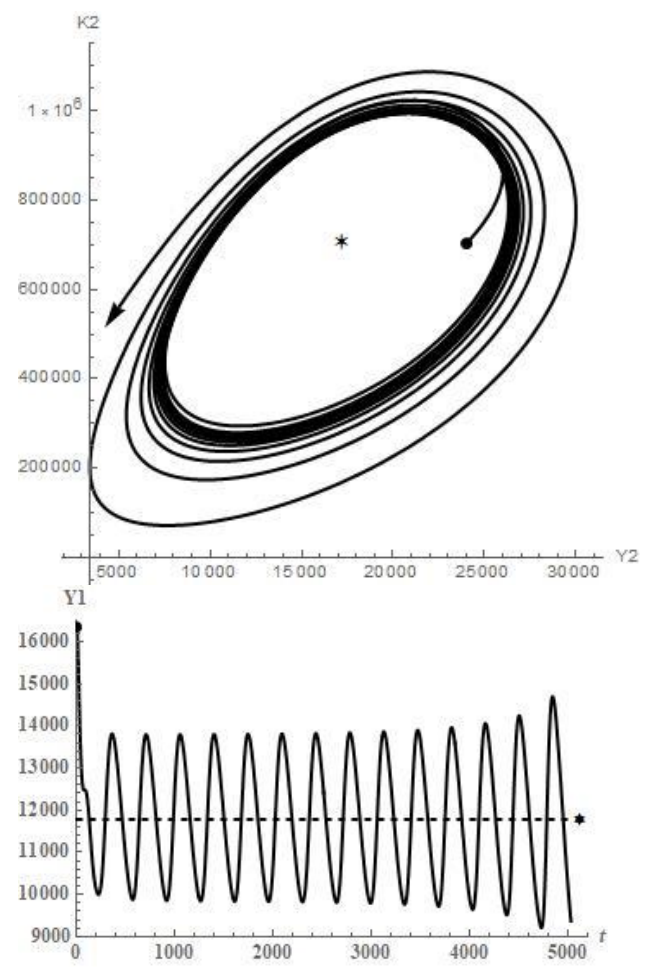



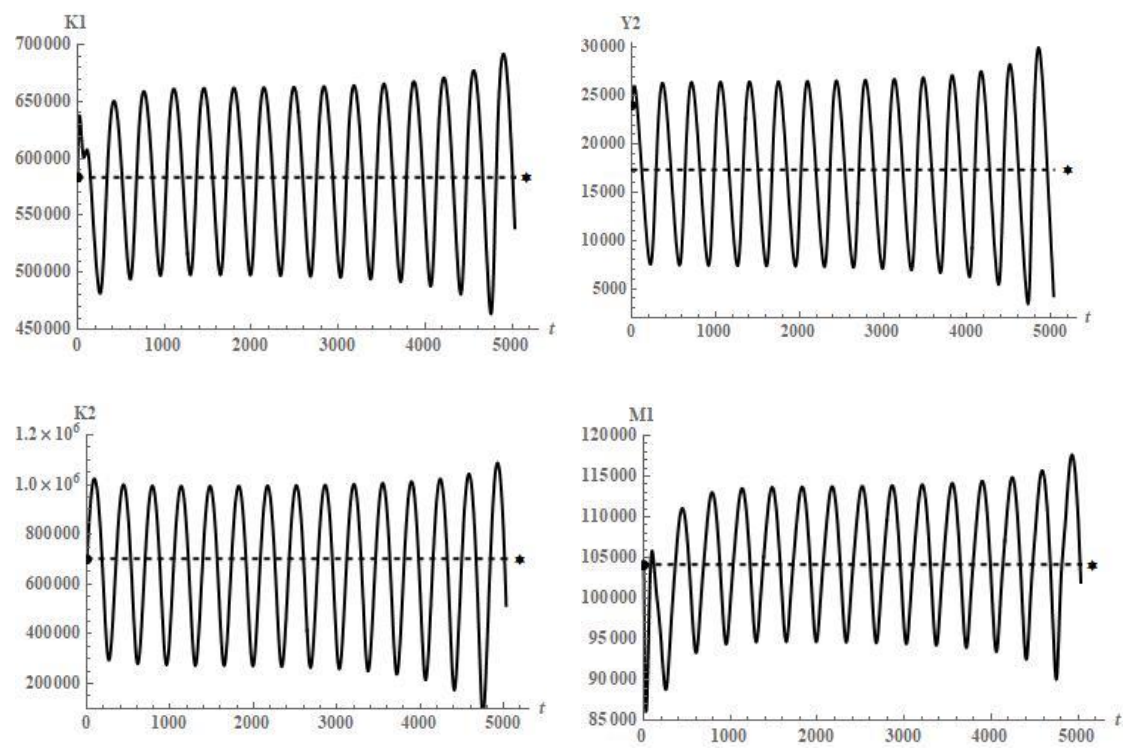

Fig. 4. The projection of the solution into the plane $O_{Y_{2}, K_{2}}$ and the courses of its individual variables at $\alpha_{2}=0.9 \alpha_{2}^{*}$ with the initial values $Y_{10}=1.3867 Y_{1}^{*}, K_{10}=K_{1}^{*}$, $Y_{20}=1.3867 Y_{2}^{*}, K_{20}=K_{2}^{*}, M_{10}=M_{1}^{*}$

Source: own elaboration.

Figure 4 shows the solution which starts in the outer part of the unstable limit cycle's repelling domain. One can see that the solution goes out of the unstable limit cycle.

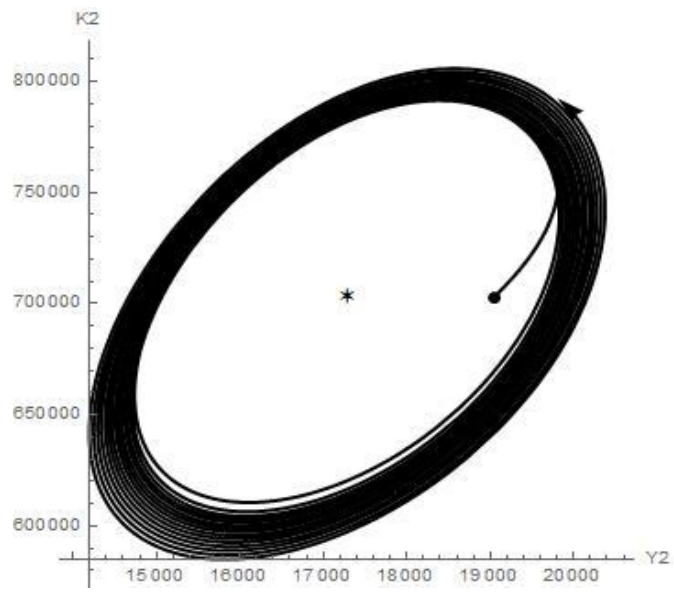


PRZEGLAD STATYSTYCZNY
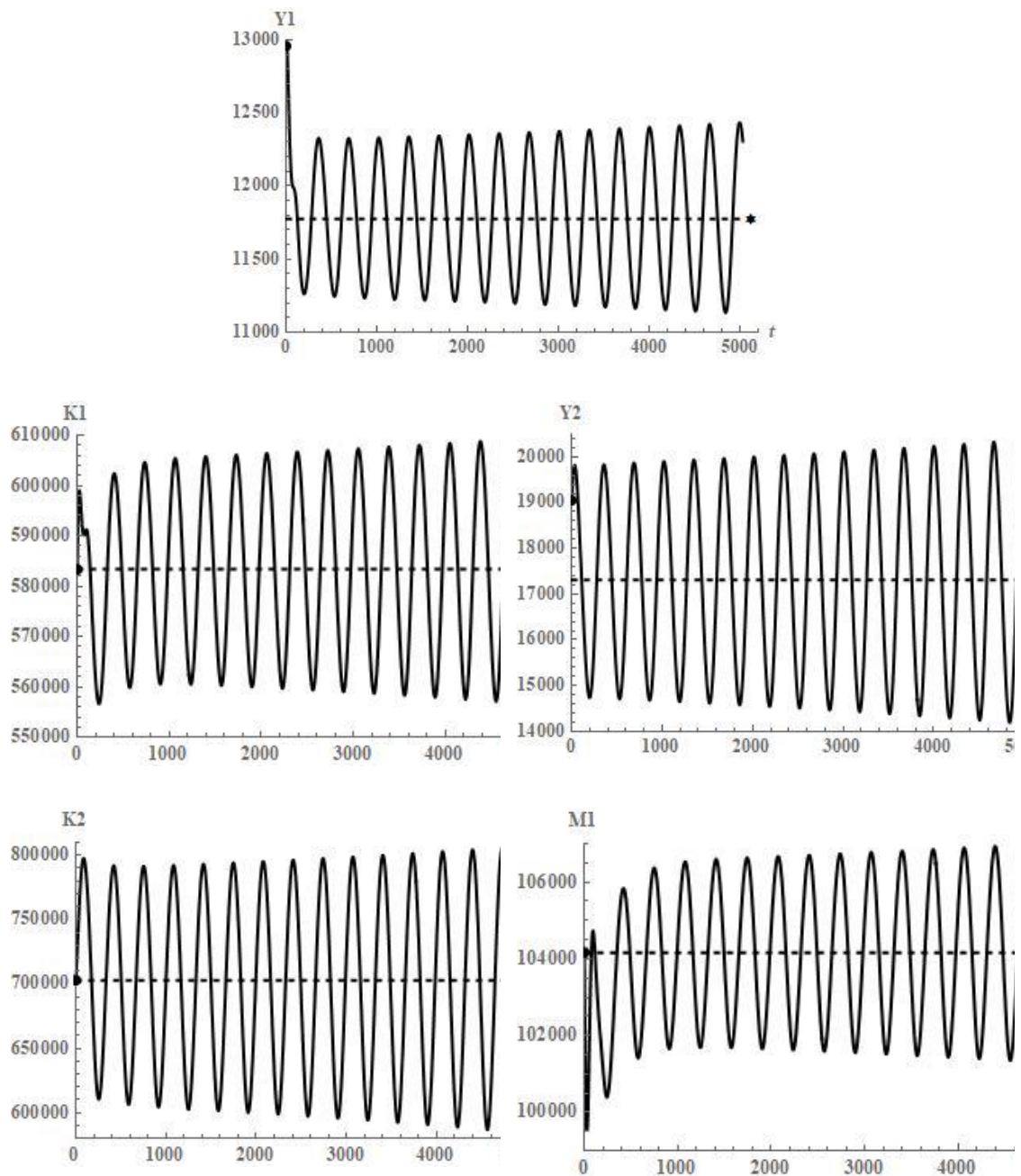

Fig. 5. The projection of the solution into the plane $O_{Y_{2}, K_{2}}$ and the courses of its individual variables at $\alpha_{2}=\alpha_{2}^{*}$ with the initial values $Y_{10}=1.1 Y_{1}^{*}, K_{10}=K_{1}^{*}$, $Y_{20}=1.1 Y_{2}^{*}, K_{20}=K_{2}^{*}, M_{10}=M_{1}^{*}$

Source: own elaboration.

Figure 5 shows the solution corresponding to the value of parameter $\alpha_{2}=\alpha_{2}^{*}$. One can see that equilibrium $\Gamma^{*}$ is unstable. At this value of parameter $\alpha_{2}$ the repelling power of equilibrium is rather weak. 

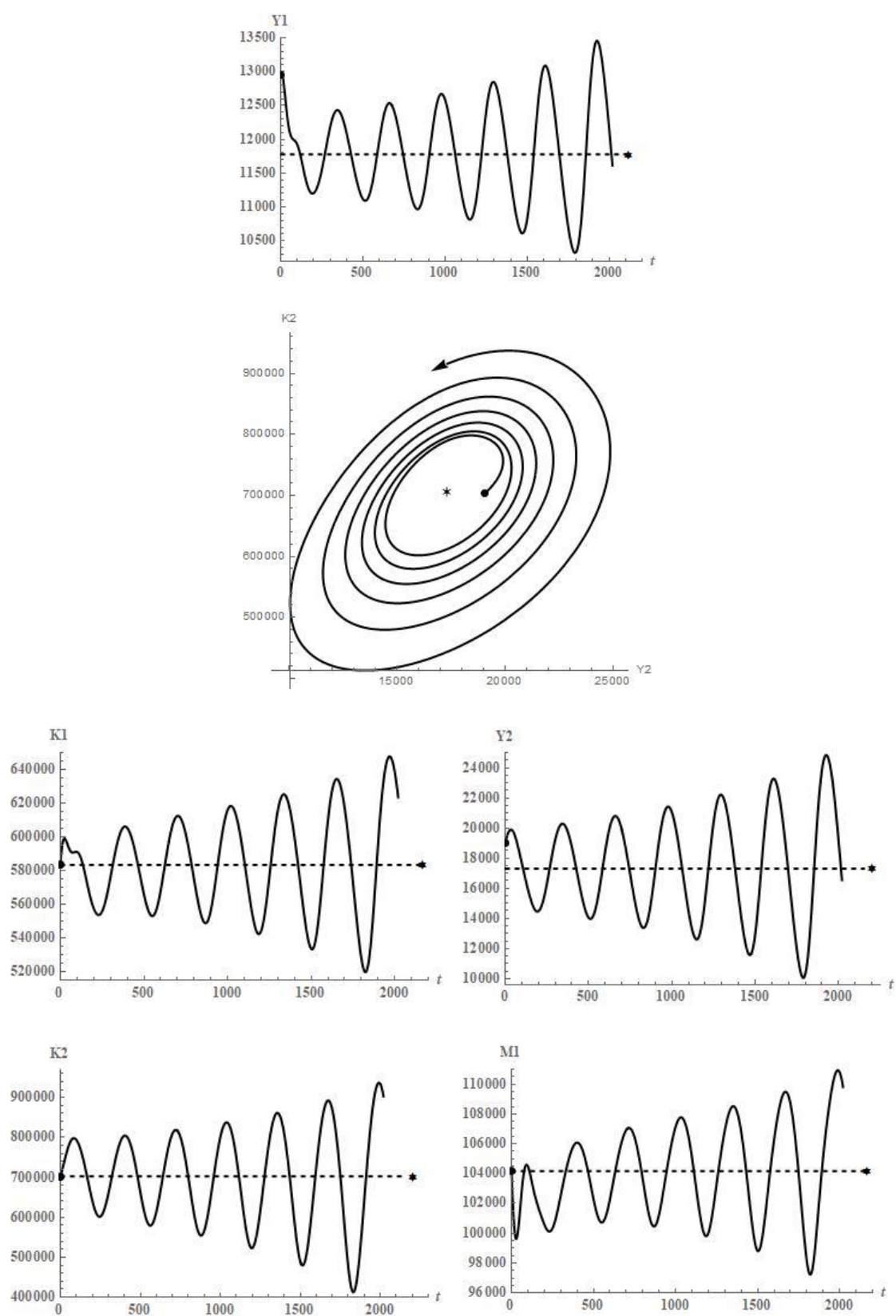

Fig. 6. The projection of the solution into the plane $O_{Y_{2}, K_{2}}$ and the courses of its individual variables at $\alpha_{2}=1.1 \alpha_{2}^{*}$ with the initial values $Y_{10}=1.1 Y_{1}^{*}, K_{10}=K_{1}^{*}$, $Y_{20}=1.1 Y_{2}^{*}, K_{20}=K_{2}^{*}, M_{10}=M_{1}^{*}$

Source: own elaboration. 
Figure 6 shows the solution corresponding to the value of parameter Nr 18(24) $\alpha_{2}=1.1 \alpha_{2}^{*}$. The repelling power of the equilibrium gets stronger with the growing distance of $\alpha_{2}$ from the value of $\alpha_{2}^{*}$. One can clearly see that now the solution goes out of the equilibrium quicker compared with the case when $\alpha_{2}=\alpha_{2}^{*}$.

\section{Conclusion}

This paper applied Asada's (2004) two-country Kaldorian non-linear macrodynamic model of business cycles to the conditions of Slovakia and the Czech Republic. It was assumed that these countries are connected through international trade and international capital movement with imperfect capital mobility under a fixed exchange rate. The aim of the paper was to find an economically reasonable equilibrium of the model, its stability/instability, and to investigate the existence of business cycles in a small neighborhood of the equilibrium. The authors connected the domain of regional economics and international macroeconomics with that of nonlinear business cycle theory.

The Introduction provides a brief history of the development of these two domains. Section 2 presents Asada's model (2004), while in Section 3 it is adapted to the needs of Slovakia and the Czech Republic. The structures of consumption functions $C_{i}$, investment functions $I_{i}$, interest rate functions $r_{i}$, tax functions $T_{i}$, and net export functions $J_{i}, i=1,2$, were set up. In Section 4 the coefficients of these functions were calculated on the basis of the quarterly data from Slovakia and the Czech Republic from the period 2010-2017. Section 5 is devoted to the analysis of the adapted model. The Jacobian matrix was constructed, the bifurcation parameter $\alpha_{2}$ and its bifurcation value $\alpha_{2}{ }^{*}$ found, and finally the bifurcation equation of the model was derived. The bifurcation equation provides all necessary information on the qualitative behaviour of the solutions of the model in a small neighborhood of its equilibrium. It is shown that to each value of parameter $\alpha_{2}, \alpha_{2}<\alpha_{2}{ }^{*}$, which is close enough to $\alpha_{2}{ }^{*}$, the equilibrium is stable, and simultaneously an unstable limit cycle arises, while the equilibrium is unstable for values $\alpha_{2} \geq \alpha_{2}{ }^{*}$. Section 6 presents numerical simulations, proving that they are fully in compliance with the obtained results.

The model can be utilized for the analysis of any two countries which conduct fairly intensive international trade and international capital movement between themselves. An investigation of the mutual macroeconomic relations between two countries can be expanded to any 
three countries which conduct among themselves intensive international

trade and international capital movement.

\section{References}

Asada, T. (1995). Kaldorian dynamics in an open economy. J. Econ., (62), 239-269.

Asada, T. (2004). Two-regional model of business cycles with fixed exchange rates: A kaldorian approach. Studies in Regional Science, 34(2), 19-38.

Asada, T., Chiarella, C., Flaschel, P., and Franke, R. (Eds.). (2003). Open economy macro dynamics: An integrated disequilibrium approach. Berlin: Springer.

Asada, T., Demetrian, M., and Zimka, R. (2018). On dynamics in a Keynesian model of monetary and fiscal policy with debt effect. Commun. Nonlinear Sci. Numer. Simul., (58), 131-146.

Asada, T., Demetrian, M., and Zimka, R. (2019). On dynamics in a Keynesian model of monetary and fiscal stabilization policy mix with twin debt accumulation. Metroeconomica, (70), 365-383.

Asada, T., Douskos, C., Kalantonis, V., and Markellos, P. (2010). Numerical exploration of Kaldorian interregional macrodynamics: Enhanced stability and predominance of period doubling under flexible exchange rates. Discrete Dyn. Nat. Soc., 1-29.

Asada, T., Douskos, C., and Markellos, P. (2011). Numerical exploration of Kaldorian interregional macrodynamics: Stability and the trade threshold for business cycles under fixed exchange rates. Nonlinear Dynamics, Psychology, and Life Sciences, (15), 105-128.

Asada, T., Inaba, T., and Misawa, T. (2000). A nonlinear macrodynamic model with fixed exchange rates: Its dynamics and noise effects. Discrete Dyn. Nat. Soc., (4), 319-331.

Asada, T. Inaba, T., and Misawa, T. (2001). An interregional dynamic model: The case of fixed exchange rates. Studies in Regional Science., (31), 29-41.

Asada, T., Kalantonis, V., Markellos, M., and Markellos, P. (2012). Analytical expressions of periodic disequilibrium fluctuations generated by Hopf bifurcations in economic dynamics. Appl. Math. Comput., (218), 7066-7077.

Asada, T., Misawa, T., and Inaba, T. (2000). Chaotic dynamics in a flexible exchange rate system: A study of noise effects. Discrete Dyn. Nat. Soc., (4), 309-317.

Bibikov, Y. N. (Eds.). (1979). Local theory of nonlinear analytic ordinary differential equations. Berlin: Springer.

Gandolfo, G. (Eds.). (2009). Economic Dynamics. Berlin: Springer.

Kaldor, N. (1940). A model of the trade cycle, Econ. J., (50), 69-86.

Kuznetsov, Yu. A. (2004). Elements of applied bifurcation theory. Berlin: Springer.

Lorenz, H. W. (1987). International trade and the possible occurrence of chaos. Economics Letters, (23), 135-138.

Lorenz, H. W. (1993). Nonlinear dynamical economics and chaotic motion. Berlin: Springer.

Maličký, P., and Zimka, R. (2010). On the existence of business cycles in Asada's tworegional model. Nonlinear Analysis: Real World, 11(4 ), 2787-2795.

Maličky, P., and Zimka, R. (2012). On the existence of Tori in Asada's two-regional model. Nonlinear Anal. Real World Appl., (13), 710-724.

Medved'ová, P. (2011). A dynamic model of a small open economy under flexible exchange rates. Acta Polytechnica Hungarica, (8), 13-26. 

STATYSTYCZNY

$\operatorname{Nr}$ 18(24)

Murakami, H. (2018). A two-sector Keynesian model of business cycles. Metroeconomica, 69(2), 444-472.

Nijkamp, P., and Reggiani, A. (Eds.). (1992). Interaction, evolution and chaos in space. Berlin: Springer.

Puu, T. (Eds.). (1997). Nonlinear Economic Dynamics. Berlin: Springer.

Rosser, Jr., J. B. (1991). From catastrophe to chaos: a general theory of economic discontinuities. Boston: Kluwer Academic Publishers.

Wiggins, S. (Eds.). (1990). Introduction to applied nonlinear dynamical systems and chaos. New York: Springer.

\section{DYNAMIKA DWUPAŃSTWOWEGO KALDORIAŃSKIEGO MODELU CYKLI BIZNESOWYCH ZE STALYMI KURSAMI WALUT: PRZYKŁAD SLOWACJI I REPUBLIKI CZESKIEJ}

Streszczenie: W niniejszym artykule analizowano pięciowymiarowy nieliniowy model Asady opisujący dynamiczne oddziaływanie dwóch regionów połączonych międzyregionalnym handlem i przepływem kapitału ze stałymi kursami wymiany zastosowany dla przypadku Słowacji i Czech. W modelu uwzględniono funkcje konsumpcji, inwestycji, stóp procentowych, podatków i eksportu netto określone na podstawie danych kwartalnych z lat 2010-2017 dla wymienionych krajów. Wyznaczono równowagę i ustalono, jakie warunki powinny spełniać parametry modelu, aby dwie spośród wartości własnych macierzy Jacobiego były czysto urojone, a pozostałe trzy miały ujemne części rzeczywiste. Określono równanie bifurkacyjne modelu, na podstawie którego można wnioskować o jakościowych własnościach rozwiązań znajdujących się w pewnych sąsiedztwie równowagi. Przedstawione symulacje numeryczne potwierdzają zgodność z uzyskanymi wynikami teoretycznymi.

Słowa kluczowe: dwupaństwowy model Kaldoriana, stałe kursy walutowe, równowaga, stabilność, cykle koniunkturalne. 